\title{
In vitro, in vivo and pharmacokinetic assessment of amikacin sulphate laden polymeric nanoparticles meant for controlled ocular drug delivery
}

\author{
Upendra Kumar Sharma • Amita Verma • \\ Sunil Kuamr Prajapati · Himanshu Pandey • \\ Avinash C. Pandey
}

Received: 20 January 2014/ Accepted: 20 February 2014/Published online: 12 March 2014

(C) The Author(s) 2014. This article is published with open access at Springerlink.com

\begin{abstract}
The rationale of current exploration was to formulate positively charged amikacin-loaded polymeric nanoparticles providing a controlled release attribute. Amikacin sulphate-loaded nanoparticles were prepared by w/o/w emulsification solvent evaporation approach succeeded by high-pressure homogenization. Two bioadhesive positively charged polymers, Eudragit ${ }^{\circledR}$ RS 100 and Eudragit $^{\circledR}$ RL 100, were used in the blend, with variable ratios of drug and polymer. The formulations were assessed in terms of particle size and zeta potential. Thermal gravimetric analysis was brought out on the samples of drug, polymer and drug polymer complex. Drug loading and release attributes of the nanoparticles were scrutinized and antimicrobial activity in contrast to Staphylococcus aureus was appraised. Ocular irritation test, in vivo ocular retention study, in vivo release profile (permeation study) and in vivo antibacterial activity of polymeric nanosuspensions were executed. No rupture consequence but a lengthened drug release was contemplated from all formulations. Amikacin sulphate release from the polymeric
\end{abstract}

U. K. Sharma $(\varangle)$ · S. K. Prajapati · A. C. Pandey

Department of Pharmaceutics, Bundelkhand University Jhansi,

284128 Jhansi, India

e-mail: ups1928@yahoo.com

A. C. Pandey

e-mail: prof.avinashcpandey@gmail.com

U. K. Sharma · A. Verma · H. Pandey

Department of Pharmaceutical Science, Faculty of Health

Sciences, Sam Higginbottom Institute of Agriculture,

Technology and Sciences, 211007 Allahabad, India

e-mail: amitaverma.dr@gmail.com

U. K. Sharma · H. Pandey · A. C. Pandey

Faculty of Science, Nanotechnology Application Centre,

University of Allahabad, 211002 Allahabad, India nanoparticles reflected a better fit with Korsmeyer-Peppas model. In the course of the antibacterial activity of nanoparticles against $S$. aureus, formulation AE1 displays the most prominent inhibitory effect as compared with marketed formulation of amikacin sulphate.

Keywords Eudragit ${ }^{\circledR}$ RS100 - Eudragit ${ }^{\circledR}$ RL100 . Polymeric nanoparticle · Amikacin - Ocular drug delivery

\section{Introduction}

Anatomically and physiologically eye is an intricate and inimitable organ cagey by a number of defensive machineries. The anatomy, physiology and biochemistry of the eye transcribe this organ immensely impervious to unfamiliar substances (Satish and Paramita 2006). Miscellaneous arrangements protecting the eye from noxious entities and agents such as lacrimation, reflex blinking, drainage, prompt tear turnover and precorneal loss ends in very dissatisfying absorption of topically executed ophthalmic drugs, as a consequence, recurrent installation of considerably concentrated solutions or suspension of drug is demanded (Emami 2006). A grave challenge to the formulator is to conquer the defending barriers of the eye without generating everlasting tissue damage, evolvement of newer, additionally responsive diagnostic systems and innovative therapeutic agents continue to provide ocular delivery systems with high therapeutic efficacy (Mitra 2009).

In the field of formulation development of ophthalmic dosage form, foremost constrained is insufficient corneal residence time of the drug molecule, consequenting in poor pharmacotherapeutics. To fix this trouble, a number of efforts were performed in the former times by formulating 
miscellaneous ophthalmic drug delivery systems in disparate formats such as hydrogels (Derwent and Mieler 2008), microparticles (Joshi 1994), nanoparticles (Nagarwal et al. 2009), liposomes (Nagarsenker et al. 1999), collagen shields (Yoel and Guy 2008), ocular inserts/discs (Bloomfield et al. 1978), dendrimers (Vandamme and Brobeck 2005) and transcorneal iontophoresis (Monti et al. 2003) etc. All of the attempts made in the history were executed with a target to defeat the swift elimination of active agent from the precorneal cavity of the eye and to boost the corneal residence time of the drug molecules. Over the last decade, diverse new drug delivery systems, such as liposomes, microparticles as well as nanoparticles, designed for the ophthalmic administration of active drug moieties, have been developed, and such formulations claim prolonged action with comfortable application of formulation in eye drop form. Nanoparticles have been established to be the most promising of all the formulations developed over the past a couple of years of marked investigations in ocular therapeutics, owing to their sustained release and prolonged therapeutic involvement. Polymeric nanoparticles are also capable of target ailments in the posterior segment of the eye (Antoine et al. 2005). Following the administration of the drug, nanoparticulate carrier can retain at the application site (cul-de-sac) and prolonged action of drug may result from drug diffusion from the particles, erosion or degradation of particles, or by the combination of both mechanisms (Soppimath et al. 2001).

Polymeric nanosuspensions were prepared from Eudragit $^{\circledR}$ RL 100 and Eudragit ${ }^{\circledR}$ RS 100 observing that they are approved by USFDA as an excipient for controlled drug delivery. Due to their competence to form nanodispersion with smaller particle size, positive surface charge, excellent stability, lack of any irritant effect on the cornea, iris and conjunctiva, Eudragit ${ }^{\circledR}$ nanoparticles come forth to be a suitable inert carrier for ophthalmic drug delivery (Haznedar and Dortunc 2004). They are inert polymer resins, insoluble at physiologic $\mathrm{pH}$ but have swelling properties. The delivery system was intended to enhance ocular availability without blurring vision and diminishing the frequency of dosing in conjunctivitis leading to patience compliance. Positive surface charge of nanoparticles can allow longer residence time for the drug on the eye surface by increasing the interaction of nanoparticles with the glycoprotein of the cornea and conjunctiva. It can form a precorneal depot resulting in the prolonged release of the bound drug from nanoparticles (Wagner and Mc-Ginity 2002; Knop 1996).

Amikacin sulphate, a potent broad spectrum antibiotic is picked as the model drug for the management of diverse acute infections of the eye, remarkably in the anterior segment, considering that it is a prime drug for the remedy of numerous grave gram-negative bacterial infections of eye and traditionally is the aminoglycoside of foremost choice on account of its low cost and reliable activity against all but the majority of resistant gram-negative bacteria. They are bacteriostatic in nature and interfere with protein synthesis in bacterial cells by binding to $30 \mathrm{~S}$ ribosomal subunit, leading to bacterial cell death (Alonso et al. 1989).

Staphylococcus aureus, most common ocular pathogen causing bacterial infection of the human cornea, was selected as test microorganism during the determination of antimicrobial activity of the prepared formulations (Armstrong 2000; Bourcier et al. 2003).

Present study was executed with a goal to evaluate the nanoparticle formation process, physicochemical properties and in vitro and in vivo activity of amikacin sulphateloaded polymeric nanoparticles prepared from Eudragit ${ }^{\circledR}$ RS 100 and RL 100 in diverse ratios. Moreover, the objective of the investigation was to formulate positively charged nanoparticles of amikacin sulphate, which could interact with the anionic mucin present in the mucus layer of the tear film.

\section{Experimental}

Materials and methods

\section{Materials, microorganism and animals}

The Eudragit ${ }^{\circledR}$ RS100 and RL100 polymers were purchased from Evonik Degussa India Private Limited (Mumbai, India) and Polyvinyl alcohol (PVA; MW 95, 000) was supplied by Sigma-Aldrich (India). Amikacin sulphate was donated as a gift sample by Cadila Pharmaceuticals Limited (Dholka, Gujarat, India). All supplementary chemicals were of reagent grade. Eudragit ${ }^{\circledR}$ RS 100 and RL 100, PVA and other chemicals were used as provided by the manufacturers without further purification. Microorganism S. aureus (ATCC 6538) was procured from Institute of Microbial Technology (Chandigarh, India). Male healthy albino rabbits having weight order of $1.5-2.0 \mathrm{~kg}$ were put to use for the amikacin ocular pharmacokinetics.

Formulation of Eudragit ${ }^{\circledR}$ RS 100/RL 100 polymeric nanoparticles

\section{Optimization of Polymer proportion and Sonication period}

Polymer ratios of Eudragit ${ }^{\circledR}$ RL 100 and RS 100 were optimized under identical experimental environment on the ground of assessment of particle size and zeta potential of 
prepared nanoparticles. In the same way, the consequences of sonication time on the entrapment efficiency and size of nanoparticles were assessed, since the period and magnitude of ultrasonication influence the size of nanoparticles, which is the most significant attribute of nanoparticles as a drug carrier.

\section{Preparation of amikacin sulphate-loaded Eudragit ${ }^{\circledR} R S$ 100/RL 100 nanoparticles}

Nanoparticles were prepared by w/o/w emulsification solvent evaporation approach immediately succeeded by highpressure homogenization (Dillen et al. 2004). Keeping drug constant at $250 \mathrm{mg}$ and varying polymer concentration, distinct ratios of drug and polymer were utilized for the preparation of nanoparticles. Individually, sample was manufactured in triplicate.

In $20 \mathrm{ml}$ of methylene chloride containing the polymer mixture of Eudragit ${ }^{\circledR}$ RL 100 and RS 100, $5 \mathrm{ml}$ of an aqueous amikacin sulphate solution $(5 \%$ w/v) was emulsified with the assistance of the ultrasound probe for $60 \mathrm{~s}$ at $40 \mathrm{~W}$. Prepared w/o emulsion was immediately poured in $25 \mathrm{ml}$ of a PVA stabilizer solution $(1 \% \mathrm{w} / \mathrm{v}$ in water), and sonicated for $60 \mathrm{~s}$ at $40 \mathrm{~W}$ to obtain a multiple emulsion. Acquired multiple emulsion was subsequently homogenized with the aid of a homogenizer (Microfluidics, Newton, USA) at a pressure of 60 bars through three cycles. Resultant emulsion was diluted in $100-\mathrm{ml}$ PVA solution $(0.2 \% \mathrm{w} / \mathrm{v}$ in water) to minimize coalescence. The mixture was persistently agitated on a magnetic stirrer for $6 \mathrm{~h}$ and $500 \mathrm{rpm}$ at room temperature to permit solvent evaporation and particle formation. To acquire isotonicity following reconstitution and for ease of redispersion of the solid nanoparticles by physical agitation, the cryoprotectant mannitol was blended in a $5 \%(\mathrm{w} / \mathrm{v})$ concentration succeeding freeze drying. The resulting nanosuspension was later on cooled down to $-20{ }^{\circ} \mathrm{C}$ and freeze dried.

Evaluation of the nanoparticles

\section{Morphological characterization}

Eudragit ${ }^{\circledR}$ nanoparticles were identified for the morphology with the facility of scanning electron microscope (SEM) (XL-30 Philips, Eindhoven, The Netherlands). The nanosuspensions were deposited on a glass disc applied on a metallic stub and evaporated under a vacuum overnight. The samples were metallized under an argon atmosphere with a 10-nm gold palladium thickness before the SEM analysis (EMITECH-K550 Sputter Coater, Houston, TX).
Nanoparticle size and zeta potential analysis

Photon correlation spectroscopy (Zetasizer, Beckman Coulter Inc., Delsa Nano 4C) was used for the determination of size distribution (polydispersity index) and zeta potential. For the size distribution, samples were appropriately diluted with filtered water $(0.2-\mu \mathrm{m}$ filter; Minisart, Germany) and analysis was carried out at a temperature of $25^{\circ} \mathrm{C}$ and scattering angle of $90^{\circ}$, while zeta potential was estimated utilizing a disposable zeta cuvette. All assessments were executed in triplicate $(n=3)$, and the standard deviation $(\mathrm{SD})$ was noted.

\section{Determination of encapsulation efficiency of nanoparticles}

For the determination of encapsulation efficiency, drugloaded nanoparticles were separated from the aqueous medium (supernatant) containing unloaded amikacin sulphate, with the help of the ultracentrifugation process for $30 \mathrm{~min}$ at $20,000 \mathrm{rpm}$ and $4{ }^{\circ} \mathrm{C}$ temperature (REMI high speed, cooling centrifuge, REMI Corporation, India). The remaining quantity of unloaded amikacin sulphate in the supernatant was estimated spectrophotometrically at $568 \mathrm{~nm}$ (Yang et al. 2005; Motwani et al. 2008). The amount of encapsulated amikacin sulphate into the nanoparticles was calculated using (Eq. 1).

$$
\begin{aligned}
& \text { Encapsulation efficiency }(\%) \\
& =\frac{\text { Total Amikacin }- \text { Free Amikacin }}{\text { Total Amikacin }} \times 100
\end{aligned}
$$

Fourier transform infrared spectroscopy (FTIR) analysis

FTIR transmission spectra of freeze-dried amikacin sulphate-loaded nanoparticles were acquired utilizing a FTIR spectrophotometer (Perkin-Elmer, USA, model BX2). Individually $\mathrm{KBr}$ disc was scanned at $4 \mathrm{~mm} / \mathrm{s}$ at a resolution of $2 \mathrm{~cm}$ over a wavenumber region of $400-4,000 \mathrm{~cm}^{-1}$. The characteristic peaks were noted for different samples.

\section{Thermal analysis}

To inquiry the thermal aspects of drug, polymers and complex of drug and polymer, thermal gravimetric analysis (TGA) approach was used. With the assistance of an automatic thermal analyzer system (Diamond TG/DTA 8.0, Perkin-Elmer, USA) TGA thermograms were achieved. Samples of drug, polymer and drug polymer complex were crimped in standard aluminium pans and heated from 40 to $500{ }^{\circ} \mathrm{C}$ (heating rate $10{ }^{\circ} \mathrm{C} / \mathrm{min}$ ) under constant purging of dry nitrogen $(20 \mathrm{ml} / \mathrm{min})$. For the reference, an empty pan sealed in the same way as the sample, was used. 
In vitro studies

\section{In vitro drug release tests}

For the assessment of drug release pattern from amikacinloaded polymeric nanoparticles a diffusion cell was used, whereby a dialysis membrane with a molecular weight cutoff of 12,000-14,000 Da (Medicell International, London, United Kingdom) divided the acceptor from the donor compartment, and the entire investigation was executed in triplicate. $5 \mathrm{ml}$ of amikacin sulphate nanosuspension holding drug equivalent to $50 \mathrm{mg}$ was deposited in donor compartment, and the acceptor compartment was stocked with $50 \mathrm{ml}$ of simulated tear fluid. Simulated tear fluid agitated magnetically at $200 \mathrm{rpm}$. Periodically, $12(0-12 \mathrm{~h})$ aliquots $(1 \mathrm{ml})$ were withdrawn from the acceptor compartment and restored by the same volume of fresh STF solution to retain a constant volume. Sink conditions were kept up during the whole study. For the quantitative analysis, UV-Vis spectrophotometry was utilized (Shimadzu UV-1800) at $568.0 \mathrm{~nm}$. All assessments were completed in triplicate and the SD was calculated.

For the statistical analysis, four principally practised mathematical models were picked out for the estimation of release of amikacin from amikacin-loaded nanoparticles, i.e. zero-order model (Eq. 2), first-order model (Eq. 3), HiguChi square root model (Eq. 4) and Korsmeyer-Peppas model (Eq. 5).

$\% Q_{\mathrm{t}} / \% Q_{\infty}=K * t$

$\% Q_{\mathrm{t}} / \% Q_{\infty}=1-\mathrm{e}^{-K * t}$

$\% Q_{\mathrm{t}} / \% Q_{\infty}=K * t^{1 / 2}$

$\% Q_{\mathrm{t}} / \% Q_{\infty}=K * t^{n}$

where $\% Q_{\mathrm{t}}$ is the percentage drug release at time $t, \% Q_{\infty}$ is the total percentage drug released, $\% Q_{t} / \% Q_{\infty}$ is the fraction of drug release at time $t ; K$ is the release rate constant and $n$ is the diffusional release exponent that could be used to characterize the different release mechanisms $[n \leq 0.45$ (Fickian diffusion), $0.45<n<1$ (anomalous transport) and $n=1$ (case II transports; i.e. zero-order release)] (Ritger and Peppas 1987; Pandey et al. 2011).

Data obtained during in vitro drug release assessment were treated complementing zero-order (cumulative amount of drug release vs time), first-order (log cumulative percentage of drug remaining vs time), Higuchi (cumulative percentage of release vs square root of time) and Korsmeyer-Peppas (log cumulative percentage of drug released vs log time) equation models. Excel 2007 (Microsoft ${ }^{\circledR}$ Corporation, Redmond, WA, USA) was used to evaluate the outcomes of in vitro drug release figures to acquire the best fit kinetic model for in vitro release.

\section{In vitro antimicrobial activity}

Assessment of antimicrobial action of formulated amikacin-loaded nanoparticles was performed taking a marketed eye drop of amikacin solution as a standard (Amipar eye drop, Bio Medica International, Ludhiana, India), and $S$. aureus (ATCC 6538) was used as a test organism. Nutrient agar was prepared and sterilized by autoclaving (at $121{ }^{\circ} \mathrm{C} /$ 15 psi pressure for $20 \mathrm{~min}$ ). $20 \mathrm{ml}$ of medium previously inoculated with the test microorganism $(0.2 \mathrm{ml}$ of stock) was transferred to the Petri plate and permitted to solidify. Following solidification, with the assistance of a sterile bored of 4-mm diameter cups were constructed on the solidified agar layer. Now a volume of the formulated amikacin nanoparticulate suspension and marketed amikacin eye drop was poured into the cups after keeping in record that both formulations contain an equivalent amount of drug. Before incubation, Petri plates were left at room temperature for $4 \mathrm{~h}$, afterwards plates were incubated at $37{ }^{\circ} \mathrm{C}$ for $24 \mathrm{~h}$. The zones of inhibition were obtained and diameter of the zone of inhibition was calculated with the assistance of an antibiotic zone finder. Figures were recorded in triplicate.

\section{In vivo studies}

Male New Zealand albino rabbits were used for in vivo studies. All the rabbits used have the weight in the range of $2.0-2.5 \mathrm{~kg}$, and they were free from any character of ocular inflammation and or gross deformities. Before performing an experiment, all the rabbits were adapted in our institution animal facility for 1 week. The rabbits were housed as per standard conditions, i.e. at $22 \pm 2{ }^{\circ} \mathrm{C}$ temperature, $50-70 \%$ relative humidity and with $12 \mathrm{~h}$ light/dark cycle. The rabbits were separately housed with plenty of food, and water provided ad libitum. The diverse in vivo studies were carried out with the approval and in accordance with the Institutional Animal Ethics Committee (IAEC) constituted as per directions of the Committee for the Purpose of Control and Supervision of Experiments on Animals (CPCSEA), under the Ministry of Animal Welfare Division, Government of India, New Delhi (Approval No. BU/ Pharm/11/32).

\section{Ocular irritation test}

Ocular irritation test for the optimized amikacin-loaded nanosuspension was evaluated by rabbit winking test (Pignatello et al. 2002). Total nine rabbits were divided into three groups. Group I as the control group received 
simulated tear fluid of $\mathrm{pH} 7.4$, group II was treated with marketed eye drop of amikacin sulphate solution, and group III was treated with optimized formulation (AEI) of nanosuspension. The $30-\mu \mathrm{l}$ formulations were instilled into the left eye of the rabbits, and the rabbits were forced to wink once to spread the formulations uniformly on the corneas. Then the frequency of rabbit winking in $5 \mathrm{~min}$ after instillation was recorded.

\section{In vivo ocular retention study}

For the ocular retention study, scanning electron microscope (SEM) (FEI Quanta 200, USA) approach was utilized. For this purpose, SEM micrograph of corneal surface and SEM micrograph of corneal surface later $6 \mathrm{~h}$ of treatment with nanosuspension were captured.

\section{Permeation study/in vivo release profile}

Three New Zealand albino rabbits were utilized for permeation study, and all the rabbits received the $30 \mu \mathrm{l}$ of optimized nanosuspension in one eye (right) and two drops of the commercial amikacin eye drop (Amipar, Bio Medica International, Ludhiana, India) as control in the left eye and eye was forced to blink three times. Employing a 28-gauge needle attached to $1-\mathrm{ml}$ tuberculin syringe, samples of aqueous humour $(50 \mu \mathrm{l})$ were collected from the anterior chamber of each eye at the time intervals of $0.5,1,2,4,8$ and $12 \mathrm{~h}$ instantly after instillation of local anaesthetic (4\% xylocaine solution). Now aqueous humour samples were centrifuged $(15,000 \mathrm{rpm}$ for $15 \mathrm{~min}$ ) and $20 \mu \mathrm{l}$ of the supernatant was examined for the drug employing UV spectrophotometer (SHIMADZU UV-1800), afterwards the rabbits were killed.

Various pharmacokinetic parameters such as maximum drug concentration $\left(C_{\max }\right)$ and the time of maximum drug concentration $\left(t_{\max }\right)$ were evaluated from concentration vs. time profiles. Employing the trapezoidal method, the area under the concentration-time curve $\left(\mathrm{AUC}_{0-12}\right)$ was estimated.

To evaluate the statistical difference between the two treatments for the extent of drug absorption in both ocular tissues $\left(\mathrm{AUC}_{0-12}\right)$ Paired $t$ test (at $p<0.01$ ) was used.

\section{In vivo antibacterial activity}

In vivo antibacterial investigation was accomplished using nutrient agar as growth medium and bacterial culture of $S$. aureus (ATCC 6538). Bacterial culture was sourced from IMTECH (Institute of Microbial Technology), Chandigarh. The bacterial culture maintained on nutrient agar on Petri dishes was sub-cultured in liquid nutrient medium, kept on the rotary flask shaker at $37^{\circ} \mathrm{C}$ and allowed to grow overnight. The inoculum so prepared was used further to produce infection in rabbits. Three groups of rabbit (six albino rabbit in each group) weighing $2.0-2.5 \mathrm{~kg}$ were selected and the bacterial inoculum of $S$. aureus was inoculated into the right eye in groups I, II and III with the help of a transfer loop. Thus, the infection was produced after 2 days. For the determination of antibacterial activity, three different preparations of amikacin sulphate were used on following groups, group, I (Control), group II (treated with amikacin sulphate-loaded nanoparticles), and group III (treated with amikacin sulphate) (Amipar, Bio Medica International, Ludhiana, India).

Physical parameters were recorded up to 6 days after treatment in all groups. After treatment of the rabbits with different preparations (i.e. nanosuspension was instilled twice a day, while the commercial amikacin solution was instilled four times a day during the study period), the rabbit's eyes were observed for discharge, redness and swelling up to 6 days.

\section{Storage stability studies}

To review the physical stability of optimized nanosuspension formulation (AE1) and dried nanoparticles (AE1*), aliquots of the nanosuspension formulation were freeze dried. $5 \% \mathrm{w} / \mathrm{v}$ mannitol was added to $100-\mathrm{ml}$ aliquots of samples as a cryoprotectant; all the aliquots were frozen in liquid nitrogen and then lyophilized (Heto Drywinner, Thermo Scientific, USA) for a period of $48 \mathrm{~h}$, at $-60{ }^{\circ} \mathrm{C}$, and $0.05 \mathrm{mmHg}$ pressure.

Physical stability protocol for the nanosuspension formulation and lyophilized nanoparticles was designed according to the standards of ICH. For this study, exact volumes of each nanosuspensions were stored in closed glass bottles for 6 months under different temperature conditions, i.e.at $5 \pm 2{ }^{\circ} \mathrm{C}$ (in refrigerator) and at $25^{\circ} \mathrm{C} /$ $60 \%$ relative humidity (RH) in dark conditions. After 6 months, aliquots of $2 \mathrm{ml}$ were withdrawn from all samples to measure particle size and drug loading.

\section{Results and discussion}

Formulation of Eudragit ${ }^{\circledR}$ RS100/RL100 polymeric nanoparticles

\section{Optimization of polymer proportion and sonication period}

For the optimization of the polymer ratio, five batches specifically F1, F2, F3, F4 and F5 having Eudragit ${ }^{\circledR}$ RS 100 and Eudragit ${ }^{\circledR}$ RL 100 ratios of 10:90, 30:70, 50:50. 70:30 and 90:10 were formulated. Following determination of particle size and zeta potential of all batches, it was 
Table 1 Optimization of polymer ratio and sonication period for amikacin sulphate-loaded polymeric nanoparticles

\begin{tabular}{|c|c|c|c|c|}
\hline $\begin{array}{l}\text { Formulation } \\
\text { batch code }\end{array}$ & $\begin{array}{l}\text { Percentage proportion of Eudragit }{ }^{\circledR} \text { RS- } \\
\text { 100:Eudragit }{ }^{\circledR} \text { RL-100 }\end{array}$ & $\begin{array}{l}\text { Sonication } \\
\text { time }(s)\end{array}$ & $\begin{array}{l}\text { Particle size } \\
(\text { mean } \pm \mathrm{SD})(\mathrm{nm})\end{array}$ & $\begin{array}{l}\text { Zeta potential }(\text { mean } \pm \mathrm{SD}) \\
(\mathrm{mV}), n=3\end{array}$ \\
\hline \multirow[t]{3}{*}{ F1 } & \multirow[t]{3}{*}{$10: 90$} & 30 & $128 \pm 22.6$ & $46.3 \pm 0.4$ \\
\hline & & 60 & $122 \pm 26.2$ & $43.2 \pm 0.3$ \\
\hline & & 90 & $126 \pm 21.7$ & $44.1 \pm 0.3$ \\
\hline \multirow[t]{3}{*}{$\mathrm{F} 2$} & \multirow[t]{3}{*}{$30: 70$} & 30 & $159 \pm 14.3$ & $42.1 \pm 0.3$ \\
\hline & & 60 & $153 \pm 16.1$ & $41.2 \pm 0.4$ \\
\hline & & 90 & $154 \pm 20.1$ & $40.6 \pm 0.2$ \\
\hline \multirow[t]{3}{*}{ F3 } & \multirow[t]{3}{*}{$50: 50$} & 30 & $184 \pm 16.3$ & $37.2 \pm 0.2$ \\
\hline & & 60 & $180 \pm 19.1$ & $35.4 \pm 0.3$ \\
\hline & & 90 & $181 \pm 18.2$ & $36.1 \pm 0.2$ \\
\hline \multirow[t]{3}{*}{$\mathrm{F} 4$} & \multirow[t]{3}{*}{$70: 30$} & 30 & $208 \pm 24.1$ & $33.2 \pm 0.4$ \\
\hline & & 60 & $202 \pm 19.3$ & $32.1 \pm 0.3$ \\
\hline & & 90 & $204 \pm 21.7$ & $32.8 \pm 0.3$ \\
\hline \multirow[t]{3}{*}{ F5 } & \multirow[t]{3}{*}{$90: 10$} & 30 & $242 \pm 24.4$ & $31.1 \pm 0.4$ \\
\hline & & 60 & $236 \pm 26.4$ & $29.8 \pm 0.2$ \\
\hline & & 90 & $238 \pm 23.7$ & $30.4 \pm 0.2$ \\
\hline
\end{tabular}

perceived that formulation F3 having Eudragit ${ }^{\circledR}$ RS 100 and Eudragit ${ }^{\circledR}$ RL 100 ratio of 1:1 was found to be most optimal since the particle size range of F3 formulation existed in mid of $180-184 \mathrm{~nm}$ and zeta potentials in the order of 35.4-37.2 mV. Rest formulations such as F4 and F5 were ranked in particle size above $200 \mathrm{~nm}$, since particle size preceding $200 \mathrm{~nm}$ is not admissible in ocular dosage form hence those formulations were rejected. On the other hand, formulations F1 and F2 hold zeta potential exceeding $40 \mathrm{mV}$ which was also not suitable for stability of formulation, as a consequence those formulations were also not considered (Table 1).

In the same way to establish the influence of sonication time on the size of nanoparticles, different formulations were sonicated for the period of 30,60 and $90 \mathrm{~s}$ at the time of preparation. On monitoring the particle size of the all prepared formulations, it was perceived that on expanding the time span of sonication from 30 to $60 \mathrm{~s}$ the dimension of nanoparticles downturns, however, on the further extension in sonication period up to $90 \mathrm{~s}$ the dimensions of nanoparticles once more steps up with a little increase in the zeta potential value (Table 1).

Probably, it takes place due to high energy generation caused by the increase in sonication time, consequenting in aggregation of nanoparticles and leads to increase in nanoparticles size. Sometimes in the condition of high energy, mechanical energy is transformed into kinetic energy, which affects the zeta potential of nanoparticles. Supplementally high energy influences the charge of the shear plane, resulting in an increase of the zeta potential. Sometime longer sonication period may bring out chemical changes in the solvent molecule's environment, which alters the size and zeta potential of nanoparticles.

The formulation code F3 with sonication time $60 \mathrm{~s}$ was found having optimum polymer ratio suitable for developing ocular drug delivery system as the mean particle size and zeta potential are well within range, i.e. particle size below $200 \mathrm{~nm}$ and zeta potential between 20 and $40 \mathrm{mV}$.

\section{Preparation of amikacin sulphate-loaded Eudragit ${ }^{\circledR} R S$ 100/RL 100 nanoparticles}

For the optimization of drug and polymer ratio for the formulation of amikacin sulphate-loaded nanoparticles, various ratios of drug and polymer were selected, specifically drug and polymer ratio of 1:1, 1:5, 1:15 and 1:20 (keeping Eudragit ${ }^{\circledR}$ RS 100/Eudragit ${ }^{\circledR}$ RL 100 polymer composition fixed at 50/50). Following formulation of Amikacin sulphate-loaded nanoparticles having all the selected proportion of drug and polymer, particle size, encapsulation efficiency, in vitro release profile and mechanism were determined for all formulations (Table 2).

Later on studying entire statistics acquired from diverse formulations, it was figured that alteration in drug and polymer proportion considerably influences the particle size, encapsulation efficiency, in vitro release profile and mechanism. Outcomes project that higher polymer ratio culminated in higher particle sizes, and increase in the drug and polymer ratio results in diminishing of encapsulation efficiencies for amikacin sulphate. Outcomes obtained in the present investigation exhibits dissimilarity in result to that publicized by Dillen et al. (2006) and Pignatello et al. 
Table 2 Evaluation parameters for amikacin sulphate-loaded nanoparticles using 50/50 Eudragit ${ }^{\circledR}$ RS 100/RL 100 ratio and different drug and polymer ratios

\begin{tabular}{lllllll}
\hline $\begin{array}{l}\text { Formulation } \\
\text { batch code }\end{array}$ & $\begin{array}{l}\text { Drug:polymer } \\
\text { ratio }\end{array}$ & $\begin{array}{l}\text { Particle size } \\
(\text { mean } \pm \text { SD }) \\
(\mathrm{nm})\end{array}$ & $\begin{array}{l}\text { Zeta potential } \\
(\mathrm{mean} \pm \mathrm{SD})(\mathrm{mV}), \\
(n=3)\end{array}$ & $\begin{array}{l}\text { Polydispersity } \\
\text { index }(\mathrm{nm} \pm \mathrm{SD})\end{array}$ & $\begin{array}{l}\text { Encapsulation efficiency } \\
(\%) \pm \mathrm{SD},(n=3)\end{array}$ & $\begin{array}{l}\text { Release efficiency } \\
\text { after 12 h }(n=3)\end{array}$ \\
\hline AE1 & $1: 1$ & $149 \pm 16.2$ & $25.69 \pm 1.4$ & $0.232 \pm 0.01$ & $80.94 \pm 2.3$ & $90.82 \pm 3.9$ \\
AE2 & $1: 5$ & $187 \pm 19.6$ & $26.83 \pm 2.2$ & $0.298 \pm 0.03$ & $79.23 \pm 2.9$ & $71.82 \pm 3.2$ \\
AE3 & $1: 10$ & $218 \pm 23.6$ & $26.62 \pm 3.1$ & $0.358 \pm 0.03$ & $78.12 \pm 2.5$ & $49.22 \pm 2.6$ \\
AE4 & $1: 15$ & $237 \pm 24.4$ & $26.13 \pm 1.9$ & $0.406 \pm 0.02$ & $76.34 \pm 2.3$ & $43.38 \pm 2.6$ \\
AE5 & $1: 20$ & $248 \pm 25.7$ & $26.91 \pm 3.3$ & $0.468 \pm 0.04$ & $72.16 \pm 2.9$ & $39.43 \pm 2.3$ \\
\hline
\end{tabular}

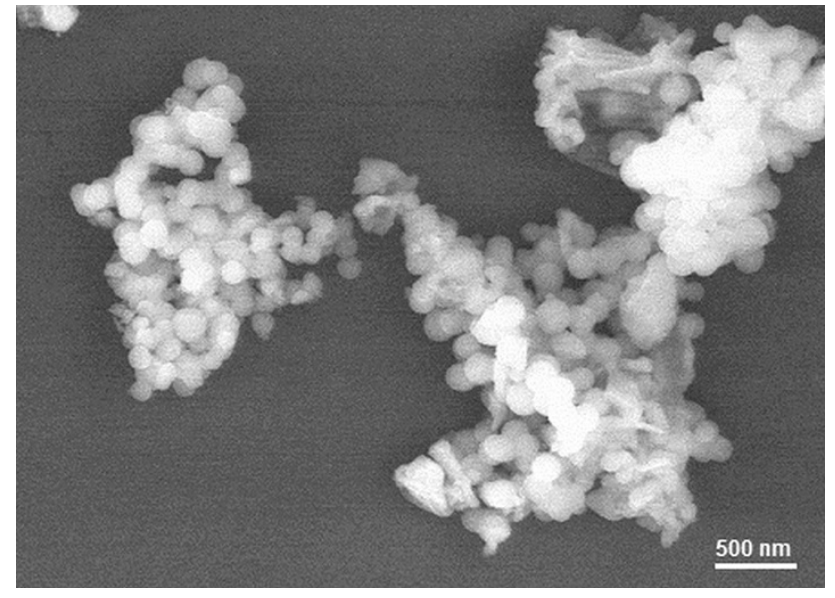

Fig. 1 SEM photomicrograph of amikacin sulphate-loaded nanoparticles

(2006), in which it was stated that the drug and polymer ratio did not influence the drug loading encapsulation efficiencies. Outcomes also project that increase in the drug and polymer ratio considerably hampered the release of Amikacin sulphate.

On behalf of aboveground, formulation having batch code AE1 of the amikacin sulphate nanoparticle suspension, that was prepared utilizing 1:1 drug to the polymer ratio exhibited the lowest mean particle size, highest drug content and release efficiency. On the ground of the abovementioned result, the nanoparticles prepared at a drug:polymer ratio of $1: 1$ and Eudragit ${ }^{\circledR}$ RS 100/Eudragit ${ }^{\circledR}$ RL 100 ratio of 50:50 (AE1) were picked out to be evaluated in vivo.

Evaluation of the nanoparticles

\section{Morphological characterization: nanoparticle size and zeta potential analysis}

Amikacin-loaded Eudragit ${ }^{\circledR}$ nanoparticles were characterized for the morphology with the help of scanning electron microscope (SEM) (XL-30 Philips, Eindhoven, The
Netherlands). SEM photomicrograph (Fig. 1) shows the presence of definite and regular nanoparticles. No sign of large aggregation was detected during a microscopic examination.

The mean particle size of formulation ranges from 149 to $248 \mathrm{~nm}$; on altering polymer ratios and keeping the drug constant, the particle size, encapsulation efficiency, in vitro release profile and mechanism influenced considerably. With the rise in the polymer ratios, the particle size raised proportionally. The results are shown in Table 1.

Results of zeta potential analysis project that every formulated batch displays positive zeta potential estimate. Since positive zeta potential is an important aspect which eases efficient adherence to the anionic mucin layer of the cornea, which consequent in lengthening of the drug release period and enhancement of the drug approachability to the ocular tissues (Pignatello et al. 2002). The mean zeta potential of nanoparticles of optimized formulation AE1 was found to be $25.69 \mathrm{mV}$, which is pondered appropriate for stability aspects.

\section{Solid-state characterization of drug polymeric system: Fourier transform infrared spectroscopy (FTIR)}

To estimate the fundamental interactions of drug to the polymer drug amikacin sulphate, polymers Eudragit ${ }^{\mathbb{B}}$ RL 100/Eudragit ${ }^{\circledR}$ RS 100 and drug-loaded polymeric nanoparticles were examined employing FTIR spectrophotometer for typical absorption bands.

The $\mathrm{N}-\mathrm{H}$ bending vibration of primary aromatic amines exhibits peaks at the $1,650-1,540 \mathrm{~cm}^{-1}$ range of the spectra. The peak at $1,637 \mathrm{~cm}^{-1}$ in both spectra of drug amikacin sulphate and amikacin sulphate-loaded polymeric nanoparticles formulation depicts that $-\mathrm{NH} 2$ group of amikacin sulphate is untreated, which represents the absence of interaction between drug and polymer. Parallelly, peaks noticed in the mid of $3,700-3,584 \mathrm{~cm}^{-1}$ in FTIR spectra of drug amikacin sulphate and amikacin sulphate-loaded polymeric nanoparticles, peak at $3,391 \mathrm{~cm}^{-1}$ represents untreated "free" hydroxyl groups 
Fig. 2 a FTIR Spectra of amikacin sulphate. b FTIR of amikacin sulphate-loaded nanoparticle
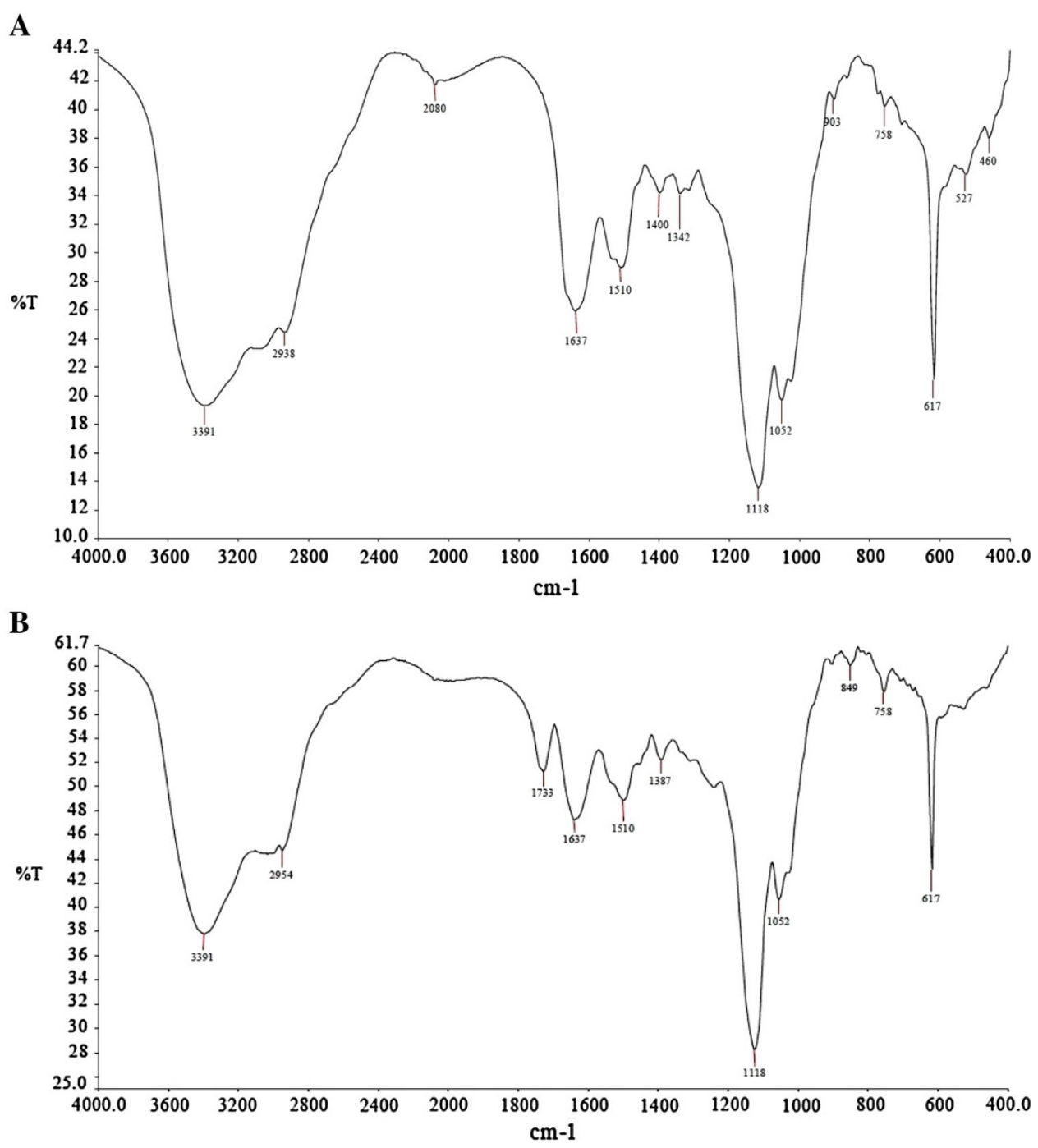

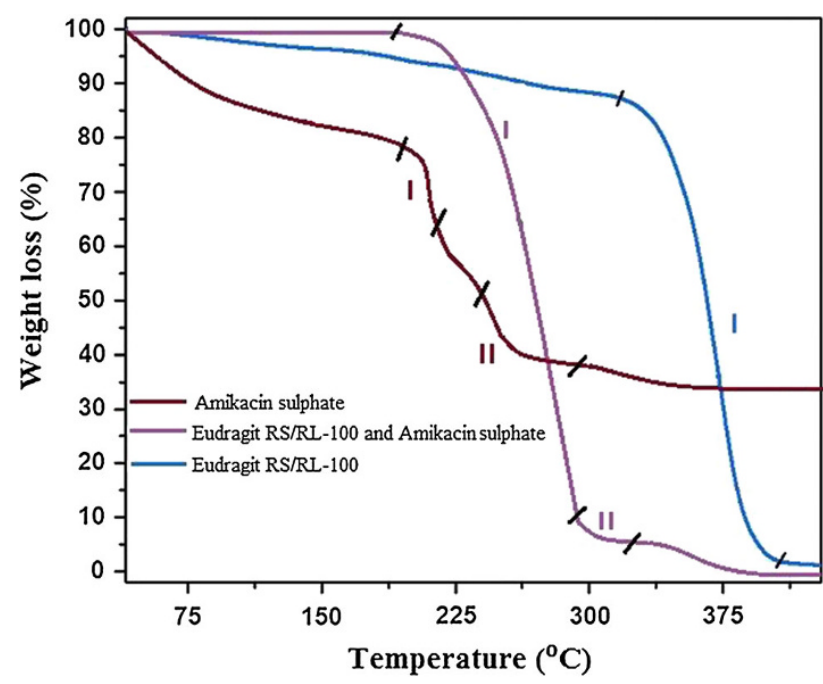

Fig. 3 Thermogravimetric analysis (TGA) of amikacin sulphate, Eudragit ${ }^{\circledR}$ RS 100/RL 100 and amikacin sulphate-loaded Eudragit ${ }^{\circledR}$ nanoparticles of amikacin sulphate. FTIR spectroscopy spectacle that there are no considerable interactions among the drug amikacin sulphate and the elected polymers Eudragit ${ }^{\circledR}$ RS 100 and Eudragit ${ }^{\circledR}$ RL 100 employed in the formulation of amikacin sulphate-loaded polymeric nanoparticles (Fig. 2a, b).

Thermogravimetric analysis (TGA)

The results from the TGA showed two significant weight losses for the amikacin sulphate below $105{ }^{\circ} \mathrm{C}$ and at $190-270{ }^{\circ} \mathrm{C}$, while the TGA curve of Eudragit ${ }^{\circledR}$ polymers showed single significant weight loss between 325 and $400{ }^{\circ} \mathrm{C}$. In contrast, the amikacin sulphate polymeric nanoparticles better thermal stability in comparison to amikacin sulphate alone. Less than $7 \%$ weight loss is observed below $200{ }^{\circ} \mathrm{C}$. Furthermore, the gradual weight loss occurs up to $295{ }^{\circ} \mathrm{C}$ (Fig. 3). 


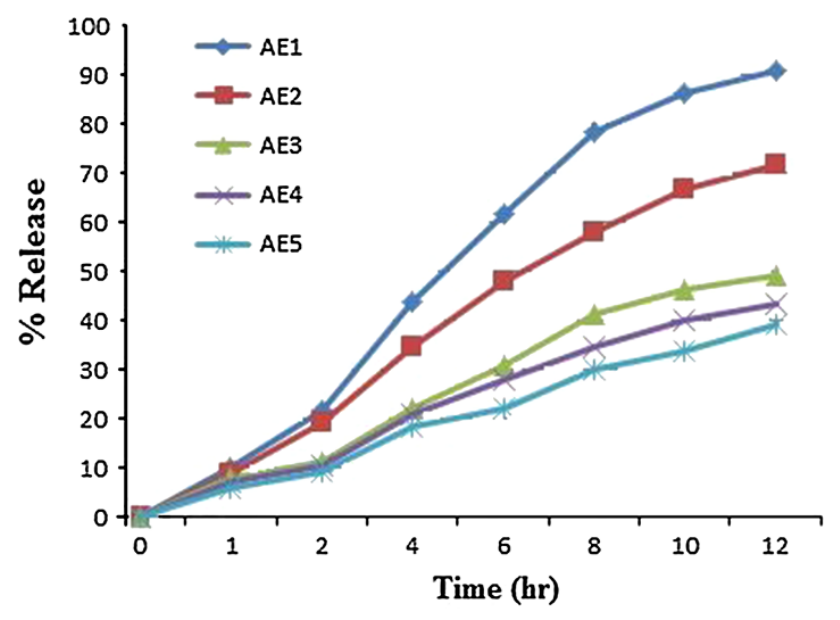

Fig. $4 \%$ Release of amikacin sulphate from different formulations

In vitro studies

\section{In vitro drug release tests}

The in vitro release study of the developed formulations AEI to AE5 was carried out for $12 \mathrm{~h}$. In these formulations, the percentage drug release was varied from 39.43 to $90.82 \%$. Release of the drug decreases, with the increase in amount of the polymers Eudragit ${ }^{\circledR}$ RL/RS 100. This may be due to the decrease in the influx of dissolution media (Fig. 4).

In vitro drug release studies revealed constant drug release and no burst effect was observed indicating that the drug was homogeneously dispersed in the Eudragit ${ }^{\circledR}$ polymeric matrix and there were no significant amount of drug adsorbed onto the surface of nanoparticles. Within all the formulations, the maximum percentage of in vitro drug release was found to be $90.82 \%$ for the formulation AEI, having drug:polymer ratio $1: 1$. The correlation coefficient $\left(r^{2}\right)$ was found to be 0.98 for AEI.

Further in order to study the mechanism of amikacin sulphate release from the polymeric nanoparticles, data obtained from the in vitro release study were fitted to various kinetic equations. The kinetic models used were a zero-order equation, first-order equation, Higuchi's square root of time equation and the Korsmeyer-Peppas equation (Table 3).

Amikacin sulphate release from the polymeric nanoparticles showed a better fit with Korsmeyer-Peppas model $\left(R^{2}=0.999,0.997,0.998,0.998\right.$ and 0.997 for formulations AEI, AE2, AE3, AE4 and AE5, respectively) contrary to the Higuchi model, zero-order model and first-order model. Fitting the release data up to $60 \%$ of the total release to the Korsmeyer-Peppas equation proposed that release of the amikacin sulphate from the polymeric matrix is through Fickian diffusion $(n=0.44,0.41,0.43,0.44$ and
0.41 for formulations $\mathrm{AEI}, \mathrm{AE} 2, \mathrm{AE} 3, \mathrm{AE} 4$ and $\mathrm{AE}$, respectively). These results suggest that the amikacin sulphate release from the polymeric nanoparticles is through diffusion.

\section{In vitro antimicrobial activity}

Diameter of the zone of inhibition by the marketed eye drop of amikacin solution was found to be $09.37 \pm 0.13 \mathrm{~mm}$ at $12 \mathrm{~h}$ and $12.24 \pm 0.19 \mathrm{~mm}$ at $24 \mathrm{~h}$, Parallelly, diameter of the zone of inhibition for the optimized amikacin sulphate polymeric nanosuspension formulation (AE1) was found to be $10.82 \pm 0.11 \mathrm{~mm}$ at $12 \mathrm{~h}$ and $13.76 \pm 0.17 \mathrm{~mm}$ at $24 \mathrm{~h}$. Results predict that developed nanosuspension possessed prolonged antimicrobial potency as compared with marketed eye drops (Fig. 5).

In vivo studies

\section{Ocular irritation test}

To grow into a realistic and successful advent for any ophthalmic drug carrier system, ocular tolerance is a noteworthy characteristic. For the same objective, in vivo ocular irritation test of amikacin sulphate-loaded polymeric nanosuspension was determined by Winking test approach. Results obtained during in vivo study exhibits that irritation effect produced by optimized formulation is almost same as of the simulated tear fluid (STF). Since no irritation effect observed in study, optimized formulation may prove a realistic and successful advent for any ophthalmic drug carrier system (Table 4).

\section{In vivo ocular retention study}

Increasing the ocular contact time is prime objective for novel ocular drug delivery systems. For in vivo ocular retention of amikacin sulphate-loaded polymeric nanoparticles, SEM micrograph of corneal surface and SEM micrograph of corneal surface later $6 \mathrm{~h}$ of treatment with nanosuspension were taken. Result displays that formulated nanosuspension $\mathrm{AE} 1$ of the amikacin sulphate exhibits corneal adherence for the long time period even after $6 \mathrm{~h}$ of application, which denotes that the optimized amikacin-loaded nanodispersion was retained for longer time span giving extended release (Fig. 6a, b).

\section{Permeation study/in vivo release profile}

On revealing the data obtained after permeation study it was observed that on treatment with commercial amikacin solution, the drug maximum concentration $\left(C_{\max }\right)$ in aqueous humour was obtained after $1 \mathrm{~h}$ whereas on

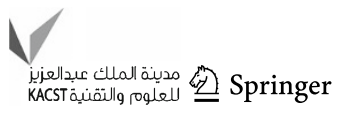




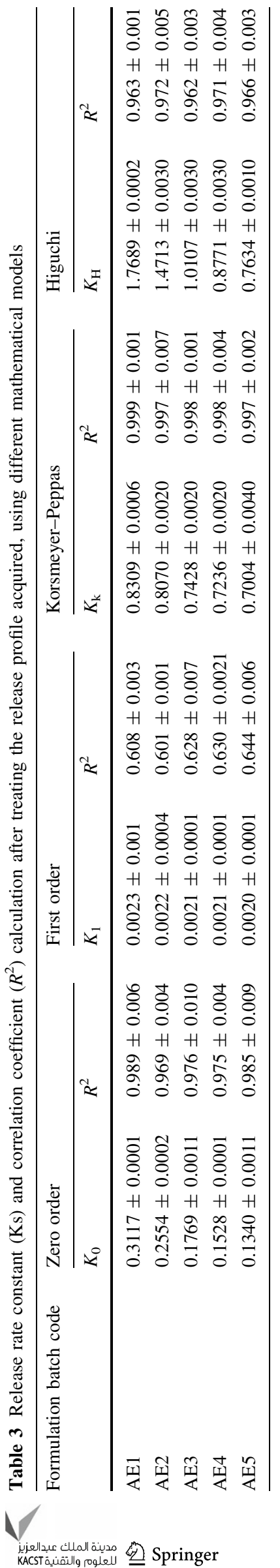

treatment with optimized nanosuspension of amikacin sulphate (AEI), drug maximum concentration $\left(C_{\max }\right)$ in aqueous humour was obtained after $2 \mathrm{~h}$. This postponement in $C_{\text {max }}$ of amikacin sulphate nanosuspension (AEI) was owing to the controlled release of the amikacin drug from the polymeric nanoparticles. Furthermore, drug maximum concentration $\left(C_{\max }\right)$ produced by nanosuspension was 1.733 time higher as compared to commercial eye drop of amikacin. In addition, bioavailability $\left(\mathrm{AUC}_{0-12}\right)$ of the nanosuspension was 2.12 time increase in comparability to the commercial eye drop (Fig. 7; Table 5).

Statistical diagnosis verified the appearance of relevant contrast among the mean $\left(\mathrm{AUC}_{0-12}\right)$ values for both treatments at $p<0.01$.

\section{In vivo antibacterial activity}

On observing the facts obtained in the end of the test, formulation $\mathrm{AE} 1$ possesses most prominent inhibiting

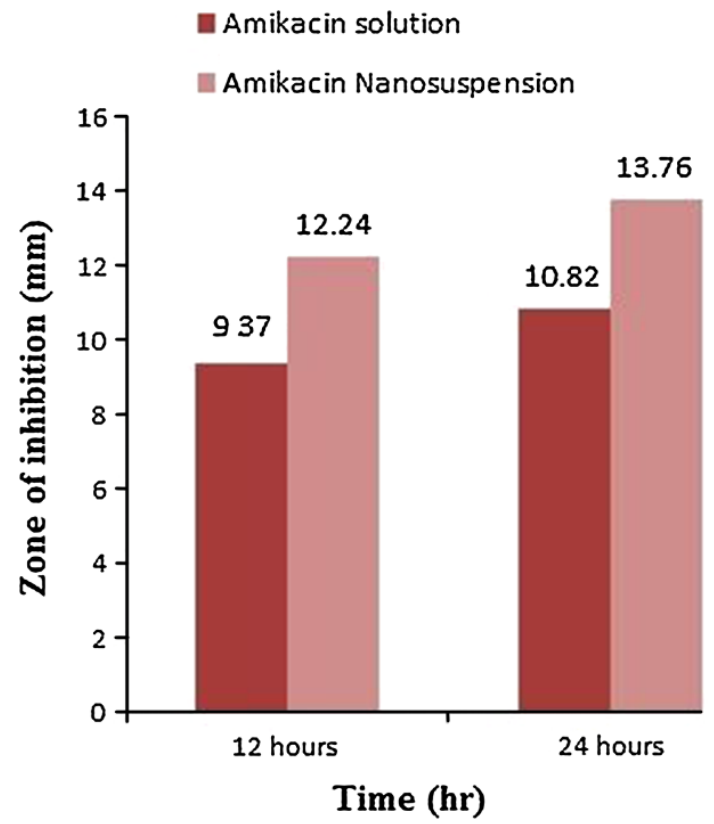

Fig. 5 Zone of Inhibition by different amikacin sulphate formulations

Table 4 Winking counts in 5 min after instillation of $30-\mu$ l samples in rabbit eyes

\begin{tabular}{llc}
\hline Groups & Formulation & $\begin{array}{l}\text { Winking count (up to } \\
5 \text { min) } n=3\end{array}$ \\
\hline I & Control (STF), pH 7.4 & $8.00 \pm 1.00$ \\
II & Commercial eye drop & $6.98 \pm 1.21$ \\
& (Amikacin sulphate) & $9.86 .0 \pm 1.13$ \\
III & Nanosuspension (AEI) &
\end{tabular}

Normal winking rate: $1-2 / \min$ 
Fig. 6 SEM photomicrograph (a) control cornea surface

(b) cornea surface after $6 \mathrm{~h}$ of treatment with nanosuspension
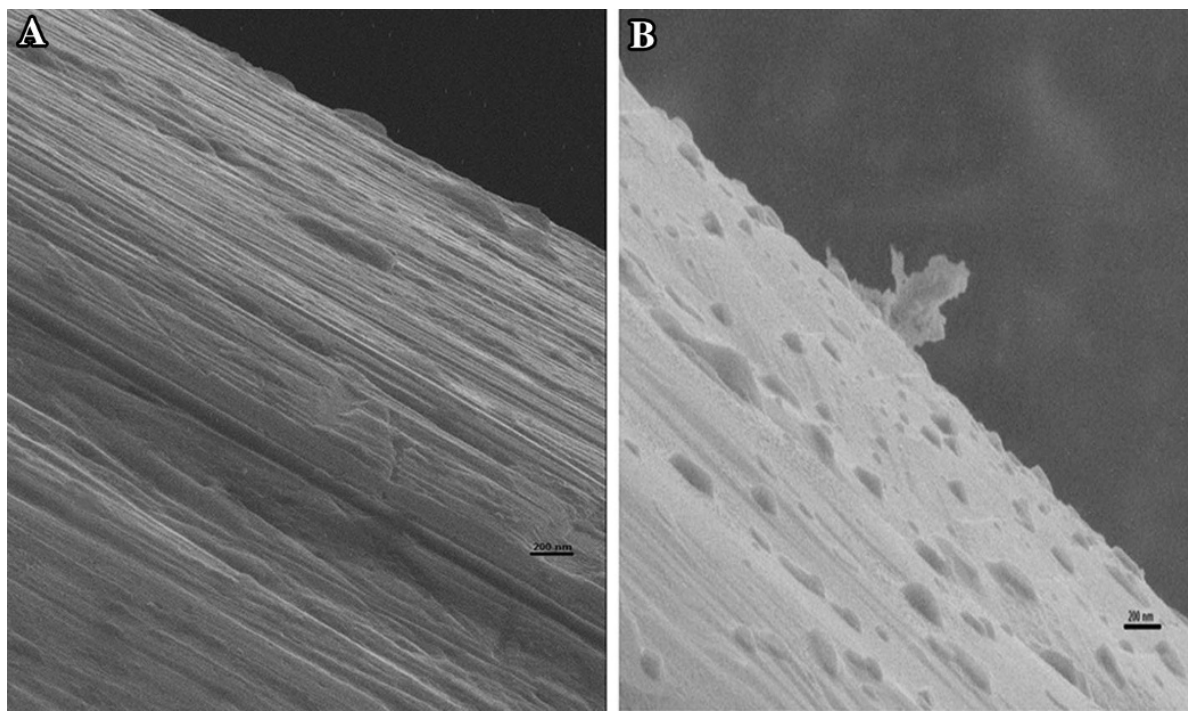

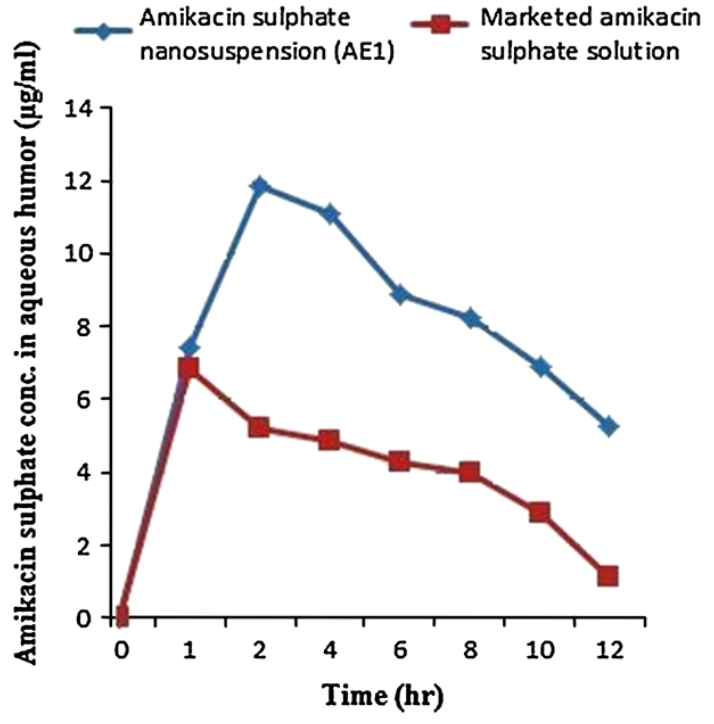

Fig. 7 Mean ocular concentration-time profile of amikacin sulphate

Table 5 Pharmacokinetic parameters for amikacin sulphate nanosuspension (AEI) and commercial amikacin sulphate solution after topical instillation in healthy rabbits

\begin{tabular}{llll}
\hline Formulation & $\begin{array}{l}C_{\max }(\mu \mathrm{g} / \\
\mathrm{ml})\end{array}$ & $\begin{array}{l}T_{\max } \\
(\mathrm{h})\end{array}$ & $\begin{array}{l}\mathrm{AUC}_{0-12} \\
(\mu \mathrm{g} \mathrm{h} / \mathrm{ml})\end{array}$ \\
\hline $\begin{array}{l}\text { Amikacin sulphate } \\
\text { nanosuspension (AEI) }\end{array}$ & $11.86 \pm 0.7$ & 2 & $80.37 \pm 2.14$ \\
\begin{tabular}{l} 
Amikacin sulphate solution \\
\hline
\end{tabular} & $06.84 \pm 0.4$ & 1 & $37.82 \pm 1.43$ \\
\hline
\end{tabular}

effect when compared with marketed formulation of amikacin sulphate. Formulation AEI of amikacin sulphate polymeric nanosuspension provides symptomatic cure after only 4 days with a dose regimen of two time in a day, at the same time the commercial amikacin solution was not able to generate complete symptomatic relief in 6 days with a dose regimen of four times in a day. This might be owing to excellent bioavailability of amikacin sulphate from the formulated nanosuspension AEI in contrast to that of commercial eye drop. Therefore, the present study proves that the formulated nanosuspension of amikacin sulphate possesses greater therapeutic outcomes than that of commercially available amikacin sulphate eye drop.

\section{Storage stability studies}

outcomes reveals that all batches after even storage exhibits mean particle sizes below $210 \mathrm{~nm}$, various reports show that particle size below $210 \mathrm{~nm}$ is appropriate for the ocular application (Amrite et al. 2008). Therefore, optimized formulations in the current study are suitable for an ocular application. Average particle size of both samples (AEI and $\mathrm{AEI}^{*}$ ), rises in a very small amount with respect to the initial values of both condition refrigerator and at $25{ }^{\circ} \mathrm{C} / 60 \% \mathrm{RH}$, it may be due to particle aggregation during the storage stage. No relevant alterations in drug content were recorded up to 6 months at both selected storage environment (Table 6).

\section{Conclusions}

Nanosuspensions were prepared by nano emulsification approach. The principal benefits of the used preparation techniques are the nullification of toxic organic solvents, 
Table 6 Storage stability studies of the optimized nanosuspension (AEI) and lyophilized nanoparticles of the optimized nanosuspension (AEI*)

\begin{tabular}{|c|c|c|c|c|c|c|}
\hline \multirow{2}{*}{$\begin{array}{l}\text { Formulation } \\
\text { batch code }\end{array}$} & \multicolumn{3}{|c|}{ Mean size $(\mathrm{nm}) \pm \mathrm{SD}$} & \multicolumn{3}{|c|}{ Drug loading $(\%) \pm \mathrm{SD}$} \\
\hline & $\begin{array}{l}\text { Initial } \\
\text { values }\end{array}$ & $\begin{array}{l}\text { After } 6 \text { months at } 5^{\circ} \mathrm{C} \\
\left( \pm 2{ }^{\circ} \mathrm{C}\right)\end{array}$ & $\begin{array}{l}\text { After } 6 \text { months at } \\
25{ }^{\circ} \mathrm{C} / 60 \% \mathrm{RH}\end{array}$ & $\begin{array}{l}\text { Initial } \\
\text { values }\end{array}$ & $\begin{array}{l}\text { After } 6 \text { months at } 5^{\circ} \mathrm{C} \\
\left( \pm 2{ }^{\circ} \mathrm{C}\right)\end{array}$ & $\begin{array}{l}\text { After } 6 \text { months at } \\
25{ }^{\circ} \mathrm{C} / 60 \% \mathrm{RH}\end{array}$ \\
\hline AEI & $149 \pm 16.2$ & $192 \pm 21.3$ & $198 \pm 19.7$ & $80.94 \pm 2.3$ & $76.92 \pm 0.7$ & $75.84 \pm 0.9$ \\
\hline AEI* & $158 \pm 19.2$ & $201 \pm 28.2$ & $203 \pm 24.2$ & $79.86 \pm 1.1$ & $74.94 \pm 0.8$ & $73.83 \pm 0.7$ \\
\hline
\end{tabular}

which increases the potential ophthalmic application of the systems. Polyvinyl alcohol (PVA) was supplemented as a stabilizing agent to the prepared formulations. Introductory experimental assessment of formulated polymeric nanoparticles in the solid state like FTIR spectroscopy and TGA validates that model drug is consistently distributed in the polymeric vehicle deprived of any interaction or polymorph change. Outcomes of FTIR analysis verify that there is no existence of unusual association forms of drug with polymers since the peak values are equivalent in both nanoparticulate systems and drug alone. Findings obtained from FTIR analysis were additionally confirmed by TGA. The temperature for the significant weight loss for the drug was equivalent to the temperature for the significant weight loss of their corresponding polymeric nanoparticles. The mean particle size of formulation ranges from 149 to $248 \mathrm{~nm}$ with polydispersity index of $0.232-0.468$ appropriate for ocular administration. In addition, TEM images showed almost spherical particles with smooth surface. The positive surface charge on the particle would provide ionic interaction with the mucous membrane of the cornea, resulting in sustained drug release and improved ocular penetration.

Drug release profile of the polymeric nanoparticles signifies that the drug release was complete with the formulated nanoparticles. Drug release profile also indicates that drug release from formulation was in controlled manner and in a common release pattern, i.e. by diffusion approach. In addition, freeze-dried nanosuspension exhibited good redispersibility upon manual handshaking; the in vitro release test was reiterated in the polymeric nano formulation succeeding 6 months of storage at $5^{\circ} \pm 2$ and $25^{\circ} \mathrm{C}, 60 \% \mathrm{RH}$; no significant dissimilarities were noticed in the magnitude of drug release. These conclusions reveal that formulated polymeric systems possess a consistent framework that was not modified considerably during storage. Supplementally, stability investigation conclusions signify that formulated polymeric nanosuspension has finer stability and improved self-life as matched to conventionally present retailed formulation.

In vivo study manifest that ocular bioavailability of the polymeric nano formulation was more than that of present trading eye drops, and polymeric nano formulations are devoid of any annoyance effect on the cornea for as long as $12 \mathrm{~h}$ following administration.

Acknowledgments The authors thank Dr. Manoj Chaurasia and Dr. Asish Gogia (Cadila Pharmaceuticals Limited, Dholka, Gujarat, India) for donating the amikacin drug. Prof. Shobhit Singh and Prof. Vijay Singh (Bundelkhand University, Department of Pharmaceutics, Jhansi, India) are gratefully acknowledge their help with spectrophotometry analysis as well as animal study.

Open Access This article is distributed under the terms of the Creative Commons Attribution License which permits any use, distribution, and reproduction in any medium, provided the original author(s) and the source are credited.

\section{References}

Alonso MJ, Losu C, Seijo B, Torres D, Vila Jato JL (1989) New ophthalmic drug release systems: formulation and ocular disposition of amikacin-loaded nanoparticles. In: 5th International Conference Pharm. Tech. 1:77-83

Amrite A, Edelhauser H, Singh S, Kompella U (2008) Effect of circulation on the disposition and ocular tissue distribution of $20 \mathrm{~nm}$ nanoparticles after periocular administration. Mol Vis $14: 150-160$

Antoine BR, Francine BC, David B, Robert G, Florence D (2005) Polymeric nanoparticles for drug delivery to the posterior segment of the eye. CHIMIA Int J Chem 59:344-347

Armstrong RA (2000) The microbiology of the eye. Ophthal Physiol Opt 20:429-441

Bloomfield SE, Miyata T, Dunn MW, Bueser N, Stenzel KH, Rubin AL (1978) Soluble gentamicin ophthalmic inserts as a drug delivery system. Arch Ophthalmol 96(5):885-887

Bourcier T, Thomas F, Borderie V, Chaumeil C, Laroche L (2003) Bacterial keratitis: predisposing factors, clinical and microbiological review of 300 cases. Br J Ophthalmol 87:834-838

Derwent JJK, Mieler WF (2008) Thermo-responsive hydrogels as a new ocular drug delivery platform to the posterior segment of eye. Trans Am Ophthalmol Soc 106:206-214

Dillen K, Vandervoort JVD, Mooter G, Verheyden L, Ludwig A (2004) Factorial design, physicochemical characterisation and activity of ciprofloxacin-PLGA nanoparticles. Int $\mathrm{J}$ Pharm 275:171-187

Dillen K, Vandervoort J, Mooter GV, Ludwig A (2006) Evaluation of ciprofloxacin-loaded Eudragit RS100 or RL100/PLGA nanoparticles. Int J Pharm 314:72-82

Emami J (2006) In vitro-in vivo correlation: from theory to applications. J Pharmacy Pharm Sci 9:169-189

Haznedar S, Dortunc B (2004) Preparation and in vitro evaluation of Eudragit microspheres containing acetazolamide. Int J Pharm 269:131-140 
Joshi A (1994) Microparticulates for ophthalmic drug delivery. J Ocul Pharmaco 10(1):29-45

Knop K (1996) Influence of buffer solution composition on drug release from pellets coated with neutral and quaternary acrylic polymers and on swelling of free polymer films. Eur J Pharm Sci 4:293-300

Mitra AK (2009) Role of transporters in ocular drug delivery system. Pharm Res 26:1192-1196

Monti D, Saccomani L, Cheton P, Burgalassi S, Saettone MF (2003) Effect of iontophoresis on transcorneal permeation 'in vitro' of two $\beta$-blocking agents, and on corneal hydration. Int J Pharm 250(2):423-429

Motwani SK, Chopra S, Talegaonkar S, Kohli K, Ahmad FJ, Khar RK (2008) Chitosan-sodium alginate nanoparticles as submicroscopic reservoirs for ocular delivery: formulation, optimization and in vitro characterization. Eur J Pharm Biopharm 68:513-525

Nagarsenker MS, Londhe VY, Nadkarni GD (1999) Preparation and evaluation of liposomal formulations of tropicamide for ocular delivery. Int J Pharm 190(1):63-71

Nagarwal RC, Kant S, Singh PN, Maiti P, Pandit JK (2009) Polymeric nanoparticulate system: a potential approach for ocular drug delivery. J Control Release 136(1):2-13

Pandey H, Parashar V, Parashar R, Rajiv Prakash R, Ramteke PW, Pandey AC (2011) Controlled drug release characteristics and enhanced antibacterial effect of graphene nanosheets containing gentamicin sulfate. Nanoscale 3:4104

Pignatello R, Bucolo C, Ferrara P, Maltese A, Puleo A, Puglisi G (2002) Eudragit RS100 nanosuspensions for the ophthalmic controlled delivery of ibuprofen. Eur J Pharm Sci 16:53-61
Pignatello R, Ricuperom N, Bucolom C, Maugeri F, Maltese A, Puglisi G (2006) Preparation and characterization of Eudragit retard nanosuspensions for the ocular delivery of cloricromene. AAPS Pharm Sci Tech 7(1):E27

Ritger PL, Peppas NA (1987) A simple equation for description of solute release I. Fickian and non-Fickian release from nonswellable devices in the form of slabs, spheres, cylinders or discs. J Controlled Release 5:23-36

Satish KS, Paramita B (2006) Pharmacia corporation. Ophthalmic formulation with novel gum composition. US Patent Number 7128928

Soppimath KS, Aminabhavi TM, Kulkarni AR, Rudzinski WE (2001) Biodegradable polymeric nanoparticles as drug delivery devices. J Controlled Rel 70:1-20

Vandamme TF, Brobeck L (2005) Poly (amidoamine) dendrimers as ophthalmic vehicles for ocular delivery of pilocarpine nitrate and tropicamide. J Control Release 102(1):23-38

Wagner KG, Mc-Ginity JW (2002) Influence of chloride ion exchange on the permeability and drug release of Eudragit RS 30 D films. J Control Rel 82:385-520

Yang YWW, Wang C, Hu J, Fu S (2005) Chitosan nanoparticles as a novel delivery system for ammonium glycyrrhizinate. Int $\mathbf{J}$ Pharm 295:235-245

Yoel G, Guy K (2008) Use of collagen shields for ocular surface drug delivery. Expert Rev Ophthalmol 3(6):627-633 